\title{
Multiple genital sebaceous cyst
}

\section{KEYWORDS: Scrotum, Sebaceous cyst}

A 50-year-old man presented since 6 months a small nodule on the scrotum that quickly got bigger and have multiplied. The patient didn't feel pain or any other symptom. The patient has been treated by the excision of all the cysts in the urology department. The anatomy pathology concluded to sebaceous cysts. The evolution was without any complications (FIGURE 1).

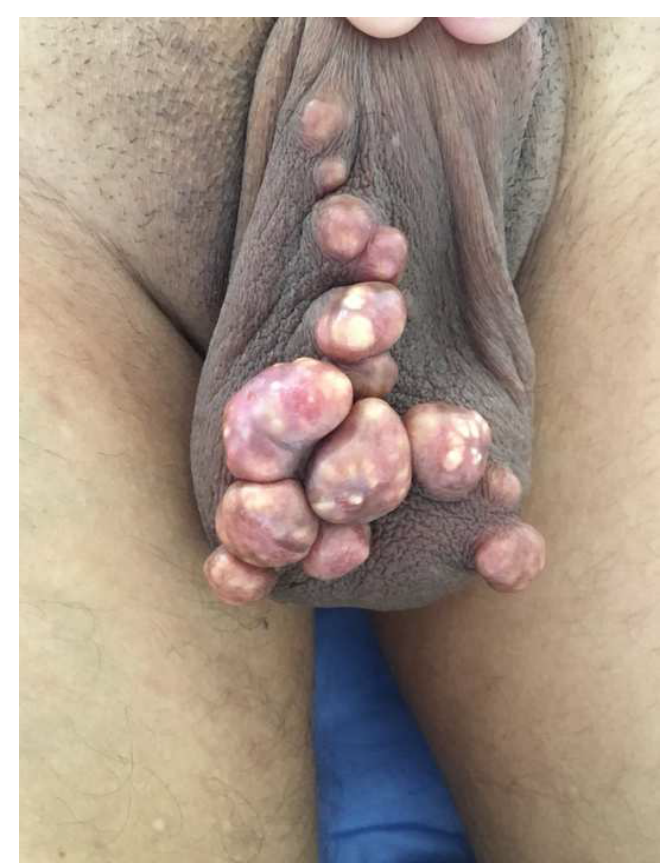

Aicha Nassiri*, Fatima Zahra Mernissi and

Omar Amrani Souhli

Centre Hospitalier Universitaire Hassan II - Fes, Morocco

*Author for correspondence:

aichanassiri6@gmail.com

Figure 1. 